\title{
UEG and EAES rapid guideline: Systematic review, meta-analysis, GRADE assessment and evidence-informed European recommendations on TaTME for rectal cancer
}

\author{
Marco Milone ${ }^{1} \cdot$ Michel Adamina $^{2,3} \cdot$ Alberto Arezzo $^{4} \cdot$ Nona Bejinariu $^{5} \cdot$ Luigi Boni $^{6} \cdot$ Nicole Bouvy $^{7}$. \\ F Borja de Lacy ${ }^{8} \cdot$ Raphaëla Dresen $^{9} \cdot$ Konstantinos Ferentinos $^{10,11} \cdot$ Nader K. Francis $^{12} \cdot$ Joe Mahaffey $^{13}$. \\ Marta Penna ${ }^{14}$. George Theodoropoulos ${ }^{15} \cdot$ Katerina Maria Kontouli ${ }^{16} \cdot$ Dimitris Mavridis $^{16,17} \cdot$ Per Olav Vandvik $^{18}$. \\ Stavros A. Antoniou ${ }^{19}$
}

Received: 14 October 2021 / Accepted: 31 December 2021 / Published online: 25 February 2022

(c) The Author(s) 2022

\begin{abstract}
Background Evidence and practice recommendations on the use of transanal total mesorectal excision (TaTME) for rectal cancer are conflicting.

Objective We aimed to summarize best evidence and develop a rapid guideline using transparent, trustworthy, and standardized methodology.

Methods We developed a rapid guideline in accordance with GRADE, G-I-N, and AGREE II standards. The steering group consisted of general surgeons, members of the EAES Research Committee/Guidelines Subcommittee with expertise and experience in guideline development, advanced medical statistics and evidence synthesis, biostatisticians, and a guideline methodologist. The guideline panel consisted of four general surgeons practicing colorectal surgery, a radiologist with expertise in rectal cancer, a radiation oncologist, a pathologist, and a patient representative. We conducted a systematic review and the results of evidence synthesis by means of meta-analyses were summarized in evidence tables. Recommendations were authored and published through an online authoring and publication platform (MAGICapp), with the guideline panel making use of an evidence-to-decision framework and a Delphi process to arrive at consensus.

Results This rapid guideline provides a weak recommendation for the use of TaTME over laparoscopic or robotic TME for low rectal cancer when expertise is available. Furthermore, it details evidence gaps to be addressed by future research and discusses policy considerations. The guideline, with recommendations, evidence summaries, and decision aids in userfriendly formats can also be accessed in MAGICapp: https://app.magicapp.org/\#/guideline/4494.

Conclusions This rapid guideline provides evidence-informed trustworthy recommendations on the use of TaTME for rectal cancer.
\end{abstract}

Keywords Rectal cancer · TaTME · Transanal TME · Clinical practice guideline · GRADE · EAES

Colorectal cancer affects a substantial proportion of the general population, with a lifetime risk of $4.3 \%$ for men and $4 \%$ for women [1]. Rectal cancer accounts for $23-32 \%$ of colorectal malignancies [2]. The anatomy of the rectum makes surgical treatment of low rectal cancer challenging. Laparoscopic surgery has been found to likely result in similar 5-year oncological outcomes and reduced minor

Marco Milone

milone.marco.md@gmail.com

Extended author information available on the last page of the article morbidity compared to open surgery [3], whereas it facilitates improved visualization for dissection deep in the pelvis. Robotic surgery has been suggested to confer further technical advantages [4].

Rectal dissection is, however, challenging in low-lying tumors and in patients with unfavorable anatomy, such as male and obese individuals. Transanal total mesorectal excision (TaTME) has been developed as an alternative technique, that allows down-to-up dissection of the rectum and perineal dissection of the mesorectum without the need for deep abdominal dissection. It has been hypothesized that this approach may improve the quality of the specimen [5]. 
TaTME has attracted much attention over the past few years and it has stimulated a debate around its safety and efficacy [6-10]. Moreover, consensus panels and practice statements have provided conflicting recommendations [11-14]. Under consideration of dissenting views and opinions, and taking into account EAES members' preferences who have prioritized colorectal cancer as a guideline topic in an online survey [15], UEG and EAES have sponsored the development of this project.

\section{Objective}

The objective of this rapid guideline was to develop reliable, trustworthy, pertinent, evidence-informed recommendations based on state-of-the-art guideline development methodology on the use of TaTME versus laparoscopic or robotic surgery in patients with rectal cancer.

\section{Methods}

The protocol of this rapid guideline is available online [16]. It was reported in accordance with AGREE II and it was developed following GRADE, Institute of Medicine and Guidelines International Network standards [17-19]. Furthermore, we adhered to GRADE guidance published in the Journal of Clinical Epidemiology as part of a series of articles detailing and updating the GRADE methodology. This guideline was facilitated with the online authoring and publication platform MAGICapp.

This is an outline of the methodology; more detailed information is provided in MAGICapp (https://app.magic app.org/\#/guideline/4767) and in the Appendix; complete datasets are available online [20].

\section{Steering group}

The guideline steering group consisted of a general surgeon performing laparoscopic, robotic and transanal TME (coordinator, MM), a certified guideline methodologist with vast experience in evidence outreach, synthesis, assessment and guideline development, (supervisor, SAA); biostatisticians (KMK, DM); and a GRADE external auditor (POV). All members of the steering group disclosed no conflicts, direct or indirect [20].

\section{Guideline panel}

The guideline panel consisted of four general surgeons, a radiation oncologist, a radiologist, a pathologist, and a patient advocate (AA, NB, NB, ED, KF, NKF, JM, GT). The patient advocate resides in the USA and was nominated by the European Patients' Forum, a non-profit umbrella organization of patient organizations across Europe. Panel members watched a short video tutorial outlining the guideline development methodology. The composition of panel members aimed to be representative of different parts of Europe, both genders, different age groups, and academic/ non-academic surgical practice. Panel members disclosed no direct nor indirect conflicts [20]. External advisors were surgeons with clinical experience and/or research focus on TaTME (MA, LB, FBdL, MP). They were consulted throughout the guideline development process, but they did not vote on the direction, the strength and the wording of the recommendations.

\section{Guideline questions}

1. Should TaTME versus laparoscopic TME be preferred for the treatment of rectal cancer?

2. Should TaTME versus robotic TME be preferred for the treatment of rectal cancer?

\section{Protocol}

A protocol was developed a priori by the steering group [16]. The protocol draft was made publicly available through the EAES website and EAES members were invited through various channels to comment on the content. The guideline questions and outcomes were refined in collaboration with the guideline panel members, whereas EAES members' comments were considered and several were addressed (see Appendix). Amendments to the protocol with justifications are provided in the Appendix.

\section{Rating the importance of outcomes}

The importance of outcomes was rated by the panel members using the GRADE scale [21]. The classification of outcomes into each of the three categories (not important, important, critical) was made by the steering group under consideration of panel members' ratings available online [20].

We considered the importance of outcomes as follows:

1. 30-day or in-hospital mortality: critical

2. 30-day complications Clavien-Dindo $\geq 3$ (major morbidity): critical

3. 30-day complications Clavien-Dindo $\leq 2$ (minor morbidity): important

4. Anastomotic leakage: critical

5. Completeness of TME: critical

6. Disease recurrence at 2 years: critical

7. 5-year overall survival: critical

8. 5-year disease-free survival: critical

9. Low anterior resection syndrome: critical 
10. Quality of life: critical

\section{Setting minimal important differences}

The evidence-to-decision framework was set within a fully contextualized approach [7]. An anonymous web-based survey of panel members was performed to define minimal important differences. The results of the survey are available online [20].

Under consideration of panel's responses, the following minimal important differences were considered:

1. 30-day or in-hospital mortality: 10 per 1000

2. 30-day complications Clavien-Dindo $\geq 3$ (major morbidity): $10-50$ per 1000

3. 30-day complications Clavien-Dindo $\leq 2$ (minor morbidity): $50-100$ per 1000

4. Anastomotic leakage: 25 per 1000

5. Completeness of TME: $25-50$ per 1000

6. Disease recurrence at 2 years: $25-50$ per 1000

7. 5-year overall survival: $10-50$ per 1000

8. 5-year disease-free survival: $10-25$ per 1000

9. Low anterior resection syndrome: 50 per 1000

10. Quality of life: score 5-10 out of 100

\section{Search strategy}

One strategy was developed for both guideline questions because of their affinity. The databases of Medline, EMBASE and OpenGrey were searched. The search syntaxes are available online [20].

\section{Study selection}

Titles and/or abstracts were screened (first level) and full text articles were scrutinized (second level) to identify eligible studies in duplicate (MM, SAA). Inclusion criteria were adult patients with adenocarcinoma of the rectum, TaTME compared with laparoscopic/robotic TME. Exclusion criteria were single incision and open surgery.

\section{Risk of bias assessment}

RoB-2 and ROBINS-I were used for risk of bias assessment in RCTs and cohort studies with a comparative arm, respectively [22, 23]. Relevant considerations are provided in the Appendix.

\section{Statistical analysis}

We conducted random effects meta-analyses to quantitatively synthesize the evidence for the guideline questions since we expected much variation in the PICO criteria across studies [25]. We explored heterogeneity via the $I^{2}$ statistic that describes the percentage of the variability of effect estimates that is due to heterogeneity rather than sampling error. We further explored heterogeneity by computing the $Q$-statistic and the $95 \%$ predictive intervals that show the plausible range of effect size values for a future trial. All the analyses were performed in $R$ statistical package version 4.0.3 using the meta package. All statistical analyses were performed independently by the statisticians' group with no involvement of the steering group or panel members.

\section{Evidence tables}

We constructed GRADE evidence profiles of certainty for each outcome separately using MAGICapp. The certainty of evidence is determined by the risk of bias across studies, incoherence, indirectness, imprecision, publication bias and other parameters [26]. We used the most recent GRADE methodology to decide on the certainty of the body of evidence from RCTs and observational studies using RoB-2 and ROBINS-I, which recommends using the judgment of high certainty of evidence at baseline and downgrading due to risk of bias of RCTs and observational studies [27]. Minimal important differences determined in advance through a survey of panel members were used to inform judgements about precision and coherence. When very low certainty evidence on an outcome was found, we used a 'systematic observation form to retrieve expert-based evidence' as previously described [28]. Evidence tables for Q1 were informed by the systematic observation form (relevant data are available online [20]), whereas experience with robotic TME was limited to provide substantial expert-based observation evidence.

\section{Evidence-to-decision framework}

The panel discussed the evidence within a GRADE evidence-to-decision framework coordinated by the guideline methodologist using MAGICapp. A formal anonymous Delphi process was carried out to finalize the judgements. A total of two online meetings were required.

\section{Developing recommendations}

Based on the evidence-to-decision framework, the panel anonymously voted on the strength and the direction of the recommendations through MAGICapp. There was unanimous consensus on the strength and the direction of the recommendations, whereas minor dissenting opinions on the wording were noted and reported accordingly in this manuscript. 


\section{Results}

Some 822 records and 46 full text articles were screened, out of which 17 met the eligibility criteria. Sixeen studies addressed Q1 [29-44] and one study addressed Q2 [45]. The study selection flowchart and considerations on record selection, and risk of bias summaries are provided in the Appendix; detailed files including discarded records with reasons, and risk of bias judgements with detailed justifications are available online [20]. Forest plots of meta-analyses are provided on MAGICapp.

Data on disease-free and overall survival were provided by one study only; local recurrence at 2 years was provided by two studies [40, 44]; however, the study was at critical risk of bias with regard to this outcome and did therefore not enter the analysis as per ROBINS-I methodology [23]. Low anterior resection syndrome and quality of life were reported by only a few studies $[35,43]$.

Several articles addressed parameters pertinent to the evidence-to-decision framework [46-53].

\section{Recommendation - TaTME versus laparoscopic TME}

\section{We suggest TaTME over laparoscopic TME if expertise} is available. Weak recommendation

\section{Rationale}

The panel identified some evidence of benefit in critical outcomes with TaTME and no evidence of harm; nevertheless, the overall certainty of the evidence was very low, primarily due to confounding bias and imprecision of effect estimates, whereas evidence on some critical outcomes, primarily survival outcomes, was very low. Substantial variability in patient values and preferences is anticipated and patient aids might be useful in this context. There is uncertainty around the use of resources, whereas equity might be reduced, due to lack of widespread expertise and longer use of operating room resources, at least during the early stages of implementation. The panel considered the intervention to be acceptable to key stakeholders, whereas feasibility was considered to vary and depend on annual volume of cases and centralization of care. An important parameter which determines the direction of the recommendation is (surgical and operating room staff) expertise. External validity of relevant research evidence is determined by the degree of expertise of surgeons and operating room staff. Consensus reports detailing training and considerations on expertise can be found here [11].

See Table 1 and full content in MAGICapp.

\section{Recommendation - TaTME versus robotic TME}

We suggest TaTME over robotic TME if expertise is available. Weak recommendation

\section{Rationale}

The panel recognized that the evidence was very limited to allow assessment of the balance between benefits and harms with confidence. Several panel members suggested that surgeon's expertise plays a vital role and probably affects outcomes, so that both options may be appropriate. Substantial variability in patient values and preferences is anticipated and shared decision making after discussion of surgeon's preference and expertise, and perceived benefits and harms is encouraged. There is uncertainty around the use of resources, which depends on whether robotic-assisted or laparoscopic-assisted TaTME is performed, and on the selection between disposable or reusable instruments for laparoscopic-assisted TaTME. Equity might be reduced, due to lack of widespread expertise and longer use of operating room resources, at least during the early stages of implementation. The panel considered the intervention to be acceptable to key stakeholders, whereas feasibility was considered to vary and depend on annual volume of cases and centralization of care. Consensus reports detailing training and considerations on expertise can be found here [11].

See Table 2 and full content in MAGICapp.

\section{Discussion}

\section{Implications for policy makers}

TaTME represents an option for the treatment of low rectal cancer, next to laparoscopic and robotic rectal resection. Although evidence on economic considerations is limited, empirical evidence does not suggest increased overall cost. Centralization of rectal cancer management may be necessary to allow accumulation of experience, which may play a vital role in operative outcomes.

\section{Implications for healthcare professionals}

Surgeons with experience in TaTME are not advised against performing TaTME in patients with low rectal cancer, as evidence from comparative observational studies which have adjusted for confounders does not indicate increased harm, moreover there is evidence of moderate certainty suggesting lower 30-day mortality and lower rate of recurrence at 3 years.

Substantial new evidence is awaited within the next few years, so that surgeons who are not trained in TaTME may not change their practice for the present. Importantly, evidence considered in this rapid guideline derives primarily from centers and surgeons with experience in TaTME; guideline users are therefore advised to exercise caution in extrapolating the evidence summarized herein. 


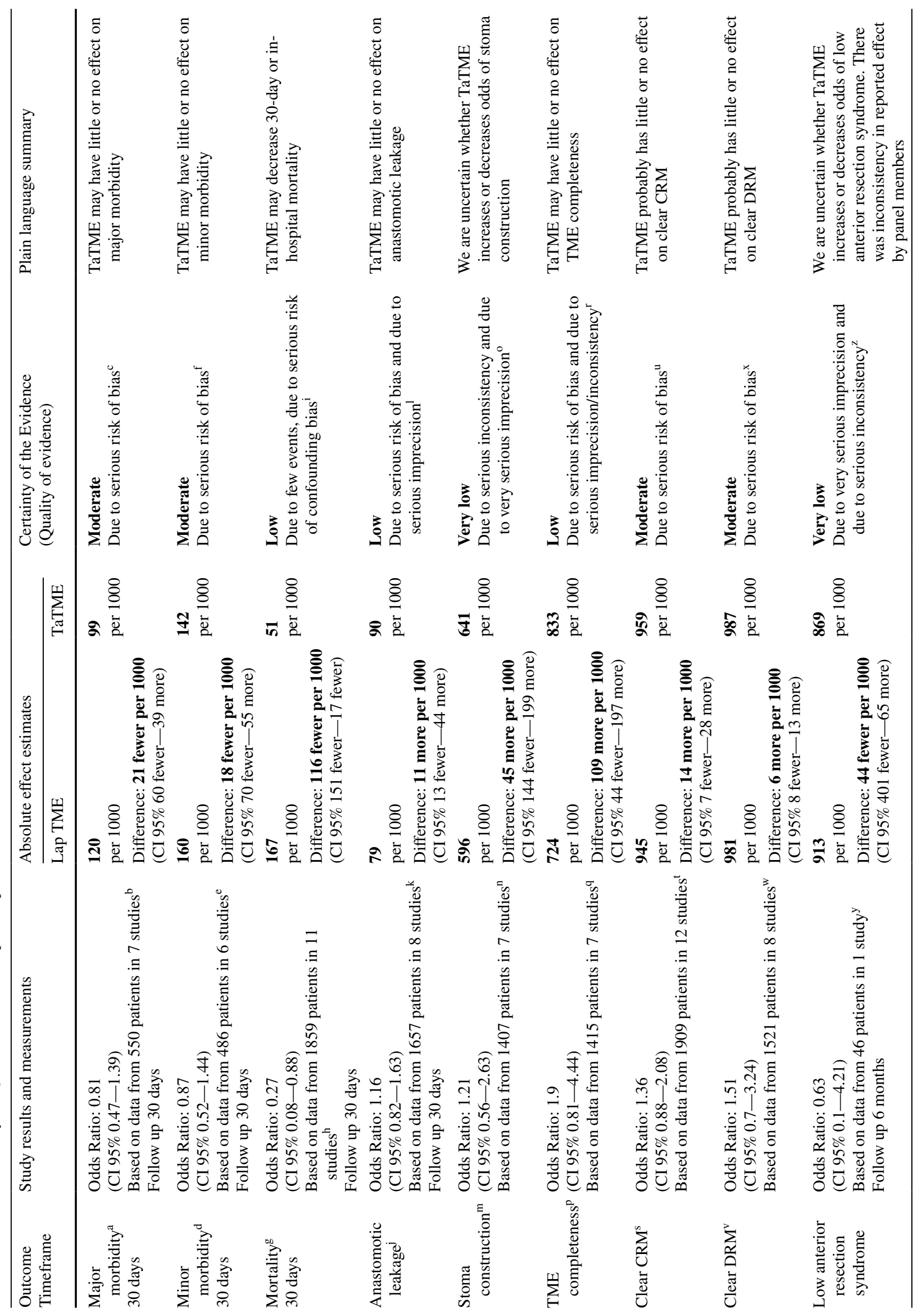




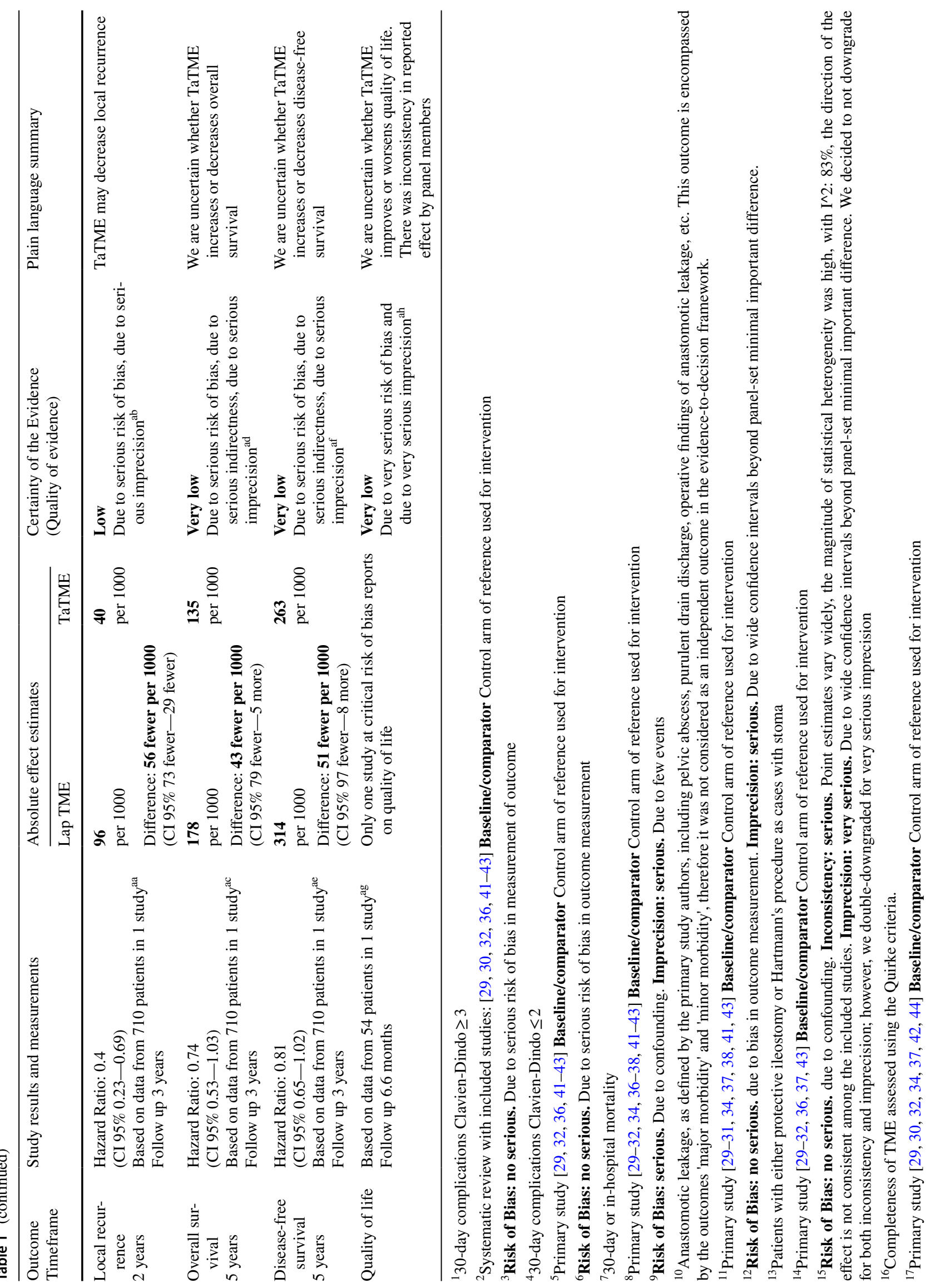




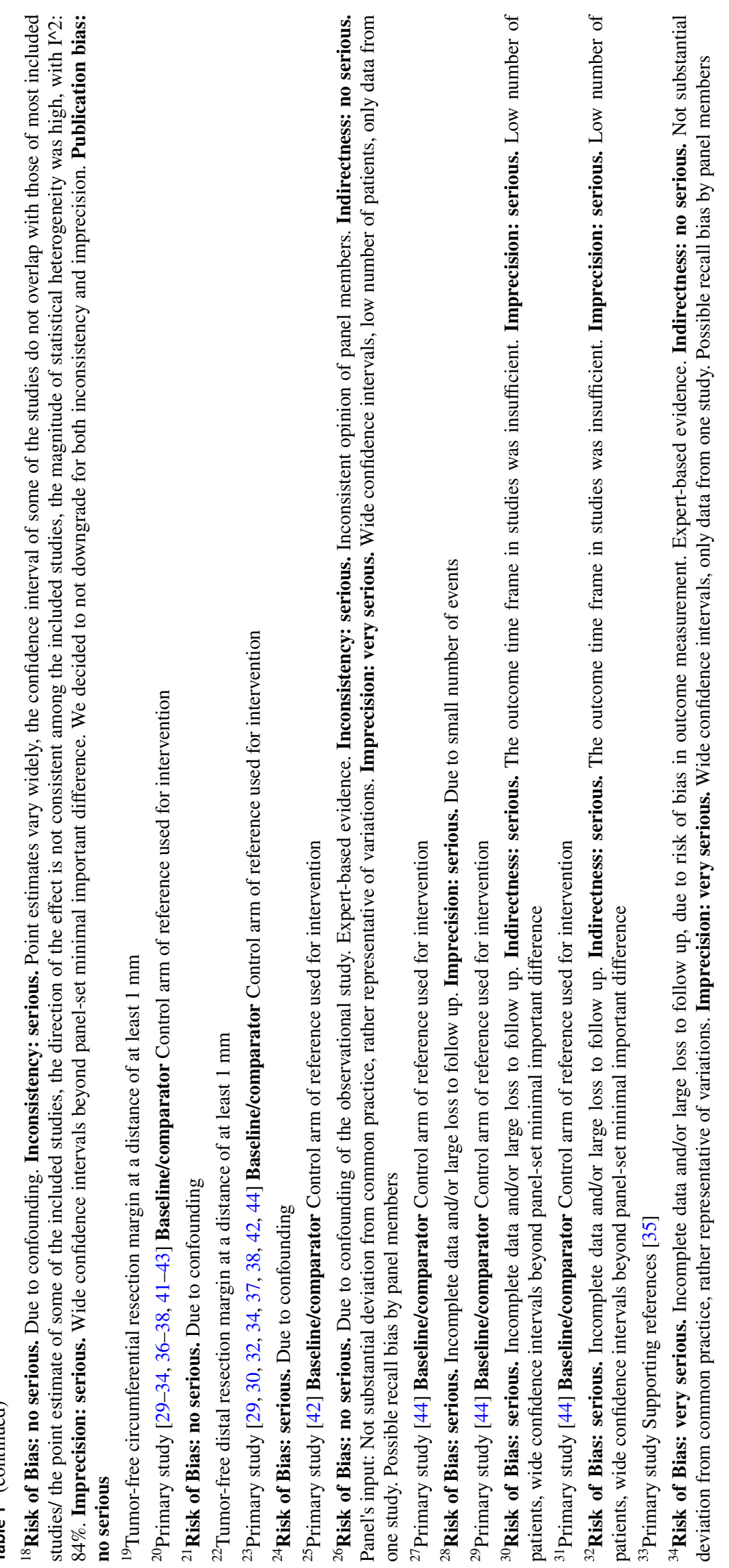


Table 2 Evidence summary on Q2: TaTME versus robotic TME

\begin{tabular}{|c|c|c|c|c|c|}
\hline \multirow{2}{*}{$\begin{array}{l}\text { Outcome } \\
\text { Timeframe }\end{array}$} & \multirow{2}{*}{$\begin{array}{l}\text { Study results and meas- } \\
\text { urements }\end{array}$} & \multicolumn{2}{|c|}{ Absolute effect estimates } & \multirow{2}{*}{$\begin{array}{l}\text { Certainty of the } \\
\text { Evidence } \\
\text { (Quality of evi- } \\
\text { dence) }\end{array}$} & \multirow[t]{2}{*}{ Plain text summary } \\
\hline & & Robotic TME & TaTME & & \\
\hline $\begin{array}{l}\text { Mortality } \\
30 \text { days }\end{array}$ & $\begin{array}{l}\text { Odds Ratio: } 0.33 \\
\text { (CI 95\% 0.02-6.81) } \\
\text { Based on data from } 596 \\
\text { patients in } 1 \text { study } \\
\text { Follow up } 30 \text { days }\end{array}$ & $\begin{array}{l}\mathbf{5} \\
\text { per } 1000 \\
\text { Difference: } \mathbf{3} \text { fe } \\
\text { (CI 95\% } 5 \text { fewe }\end{array}$ & $\begin{array}{l}\mathbf{2} \\
\text { per } 1000 \\
\mathbf{0 0 0} \\
\text { re) }\end{array}$ & $\begin{array}{l}\text { Very low } \\
\text { Due to very seri- } \\
\text { ous imprecision }^{\mathrm{c}}\end{array}$ & $\begin{array}{l}\text { We are uncertain whether } \\
\text { TaTME increases or decreases } \\
\text { mortality }\end{array}$ \\
\hline Anastomotic leakage $^{\mathrm{d}}$ & $\begin{array}{l}\text { Odds Ratio: } 1.12 \\
\text { (CI 95\% 0.65-1.91) } \\
\text { Based on data from } 596 \\
\text { patients in } 1 \text { study }\end{array}$ & $\begin{array}{l}\mathbf{1 0 0} \\
\text { per } 1000 \\
\text { Difference: } 11 \\
\text { (CI 95\% } 33 \text { few }\end{array}$ & $\begin{array}{l}\mathbf{1 1 1} \\
\text { per } 1000 \\
\mathbf{1 0 0 0} \\
\text { ore) }\end{array}$ & $\begin{array}{l}\text { Very low } \\
\text { Due to serious risk } \\
\text { of bias and due } \\
\text { to very serious } \\
\text { imprecision }\end{array}$ & $\begin{array}{l}\text { We are uncertain whether } \\
\text { TaTME increases or decreases } \\
\text { odds of anastomotic leakage }\end{array}$ \\
\hline Stoma construction ${ }^{\mathrm{g}}$ & $\begin{array}{l}\text { Odds Ratio: } 3.6 \\
\text { (CI 95\% 1.97-6.55) } \\
\text { Based on data from } 596 \\
\text { patients in } 1 \text { study }\end{array}$ & $\begin{array}{l}\mathbf{8 0 8} \\
\text { per } 1000 \\
\text { Difference: } \mathbf{1 3 0} \\
\text { (CI 95\% } 84 \text { mo }\end{array}$ & $\begin{array}{l}\mathbf{9 3 8} \\
\text { per } 1000 \\
\mathbf{1 0 0 0} \\
\text { hore) }\end{array}$ & $\begin{array}{l}\text { Very low } \\
\text { Due to very seri- } \\
\text { ous imprecision }\end{array}$ & $\begin{array}{l}\text { We are uncertain whether } \\
\text { TaTME increases or decreases } \\
\text { odds of stoma construction }\end{array}$ \\
\hline TME completeness $^{\mathrm{j}}$ & $\begin{array}{l}\text { Odds Ratio: } 0.48 \\
\text { (CI 95\% } 0.23-1.0) \\
\text { Based on data from } 596 \\
\text { patients in } 1 \text { study } \\
\end{array}$ & $\begin{array}{l}\mathbf{9 6 2} \\
\text { per } 1000 \\
\text { Difference: } \mathbf{3 8} \\
\text { (CI 95\% } 109 \mathrm{fe}\end{array}$ & $\begin{array}{l}\mathbf{9 2 4} \\
\text { per } 1000 \\
\mathbf{1 0 0 0} \\
\text { wer) }\end{array}$ & $\begin{array}{l}\text { Very low } \\
\text { Due to very seri- } \\
\text { ous imprecision }\end{array}$ & $\begin{array}{l}\text { We are uncertain whether } \\
\text { TaTME increases or decreases } \\
\text { odds of TME completeness }\end{array}$ \\
\hline Clear $\mathrm{CRM}^{\mathrm{m}}$ & $\begin{array}{l}\text { Odds Ratio: } 1.07 \\
\text { (CI } 95 \% 0.52-2.23 \text { ) } \\
\text { Based on data from } 596 \\
\text { patients in } 1 \text { study }\end{array}$ & $\begin{array}{l}\mathbf{9 4 3} \\
\text { per } 1000 \\
\text { Difference: } \mathbf{4} \mathbf{~ m} \\
\text { (CI 95\% } 47 \mathrm{few}\end{array}$ & $\begin{array}{l}\mathbf{9 4 7} \\
\text { per } 1000 \\
\mathbf{0 0 0} \\
\text { ore) }\end{array}$ & $\begin{array}{l}\text { Very low } \\
\text { Due to very seri- } \\
\text { ous imprecision }\end{array}$ & $\begin{array}{l}\text { We are uncertain whether } \\
\text { TaTME increases or decreases } \\
\text { odds of clear CRM }\end{array}$ \\
\hline Clear DRM ${ }^{\mathrm{p}}$ & $\begin{array}{l}\text { Odds Ratio: } 0.15 \\
\text { (CI 95\% 0.02-1.35) } \\
\text { Based on data from } 596 \\
\text { patients in } 1 \text { study }\end{array}$ & $\begin{array}{l}\mathbf{9 9 7} \\
\text { per } 1000 \\
\text { Difference: } \mathbf{1 7} \\
\text { (CI 95\% } 128 \mathrm{fe}\end{array}$ & $\begin{array}{l}\mathbf{9 8 0} \\
\text { per } 1000 \\
\mathbf{1 0 0 0} \\
\text { ore) }\end{array}$ & $\begin{array}{l}\text { Very low } \\
\text { Due to very seri- } \\
\text { ous imprecision }\end{array}$ & $\begin{array}{l}\text { We are uncertain whether } \\
\text { TaTME increases or decreases } \\
\text { odds of clear DRM }\end{array}$ \\
\hline $\begin{array}{l}\text { Major morbiditys } \\
30 \text { days }\end{array}$ & & & & & $\begin{array}{l}\text { No studies were found that } \\
\text { looked at major morbidity }\end{array}$ \\
\hline $\begin{array}{l}\text { Minor morbidity }{ }^{t} \\
30 \text { days }\end{array}$ & & & & & $\begin{array}{l}\text { No studies were found that } \\
\text { looked at minor morbidity }\end{array}$ \\
\hline $\begin{array}{l}\text { Local recurrence }^{\mathrm{u}} \\
2 \text { years }\end{array}$ & & & & & $\begin{array}{l}\text { No studies were found that } \\
\text { looked at local recurrence at } \\
2 \text { years }\end{array}$ \\
\hline $\begin{array}{l}\text { Overall survival } \\
5 \text { years }\end{array}$ & & & & & $\begin{array}{l}\text { No studies were found that } \\
\text { looked at 5-year overall } \\
\text { survival }\end{array}$ \\
\hline $\begin{array}{l}\text { Disease-free survival } \\
5 \text { years }\end{array}$ & & & & & $\begin{array}{l}\text { No studies were found that } \\
\text { looked at } 5 \text {-year disease-free } \\
\text { survival }\end{array}$ \\
\hline $\begin{array}{l}\text { Low anterior resection } \\
\text { syndrome }\end{array}$ & & & & & $\begin{array}{l}\text { No studies were found that } \\
\text { looked at low anterior resec- } \\
\text { tion syndrome }\end{array}$ \\
\hline Quality of life & & & & & $\begin{array}{l}\text { No studies were found that } \\
\text { looked at quality of life }\end{array}$ \\
\hline
\end{tabular}

\footnotetext{
${ }^{1} 30$-day or in-hospital mortality

${ }^{2}$ Primary study [41] Baseline/comparator Control arm of reference used for intervention

${ }^{3}$ Imprecision: Very serious. Wide confidence intervals, low number of patients, only data from one study

${ }^{4}$ Anastomotic leakage, as defined by the primary study authors, including pelvic abscess, purulent drain discharge, operative findings of anastomotic leakage, etc. This outcome is encompassed by the outcomes 'major morbidity' and 'minor morbidity'; therefore it was not considered as an independent outcome in the evidence-to-decision framework

${ }^{5}$ Primary study [41] Baseline/comparator Control arm of reference used for intervention
}

${ }^{6}$ Risk of Bias: No serious. Due to risk of bias in outcome measurement. Imprecision: Very serious. Wide confidence intervals, low number of patients, only data from one study 
Table 2 (continued)

${ }^{7}$ Patients with either protective ileostomy or Hartmann's procedure as cases with stoma

${ }^{8}$ Primary study [41] Baseline/comparator Control arm of reference used for intervention

${ }^{9}$ Imprecision: Very serious. Only data from one study

${ }^{10}$ Completeness of TME assessed using the Quirke criteria

${ }^{11}$ Primary study [41] Baseline/comparator Control arm of reference used for intervention

${ }^{12}$ Imprecision: Very serious. Wide confidence intervals beyond panel-set minimal important differences, only data from one study

${ }^{13}$ Tumor-free circumferential resection margin at a distance of at least $1 \mathrm{~mm}$

${ }^{14}$ Primary study [41] Baseline/comparator Control arm of reference used for intervention

${ }^{15}$ Imprecision: Very serious. Wide confidence intervals, only data from one study

${ }^{16}$ Tumor-free distal resection margin at a distance of at least $1 \mathrm{~mm}$

${ }^{17}$ Primary study [41] Baseline/comparator Control arm of reference used for intervention

${ }^{18}$ Imprecision: Very serious. Wide confidence intervals, only data from one study

${ }^{19}$ 30-day complications Clavien-Dindo $\geq 3$

${ }^{20} 30$-day complications Clavien-Dindo $\leq 2$

${ }^{21} 30$-day complications Clavien-Dindo $\leq 2$

\section{Implications for patients}

Patients can be informed that available evidence suggests similar outcomes between TaTME and laparoscopic TME, whereas 30-day mortality and 3-year loco-regional recurrence may be lower with TaTME if the surgeon has experience with this technique. Furthermore, they may want to discuss expected benefits and potential harms, and their surgeon's experience and preference.

\section{Implications for researchers}

There are important gaps in evidence, which are expected to be addressed by future research:

TaTME v. laparoscopic TME De novo RCTs may not be necessary, because several trials are currently underway and their results are expected to be published within the next years (see Validity period below). Matched cohort studies are needed to address the outcomes major morbidity, 30-day or in-hospital mortality, 2-year recurrence, 5-year diseasefree and overall survival, low anterior resection syndrome and quality of life. Importantly, further reports of unmatched cohorts do not contribute reliable information to the body of evidence and may be redundant and potentially misleading. Researchers may want to consider performing analyses that have adjusted for sex, BMI, ASA classification, tumor stage and distance from anal verge, and neoadjuvant chemoradiotherapy. To reach sufficient sample size, multi-institutional collaborations or registry analyses are encouraged. Analyses of male patients, patients who underwent neoadjuvant chemoradiotherapy and level (height) up to which transanal dissection was performed are expected to address the outcomes of TaTME in these subgroups.

TaTME v. robotic TME Available evidence is extremely limited and the same research considerations apply here as well. Critical and important outcomes as listed in the Methods section are expected to be addressed.

\section{Monitoring}

Use of the guideline by EAES members will be monitored through an online survey 2 years after publication. Feedback from target users in the form of email communication, letters to the editor, and comments in social media will be documented to be addressed by future versions.

\section{Validity period}

A scoping search of ClinicalTrials.gov, EU Clinical Trials Register, WHO International Clinical Trials Registry Platform, EORTC and ISRCTN registry identified at least 5 ongoing RCTs comparing TaTME with laparoscopic $(n=4)$ or robotic $(n=1)$ TME, including two mega-trials (planned to recruit $>1000$ patients each) [54-58]. Completion dates range from June 2021 to July 2025. Under consideration of the reported follow-up duration of critical outcomes, substantial new evidence is expected by 2025 for Q1 and by 2026 for Q2. The validity of the present version of this rapid guideline is set until December 2025. Please read the Disclaimer for further information regarding validity.

\section{Update}

An update of this rapid guideline is planned to take place in 2025. However, one could anticipate a change in the direction or the strength of the recommendation when data from cohort studies or registries become available, under the condition that their methodological quality will be high. The EAES Research Committee/Guidelines Subcommittee will 
keep monitoring new evidence and update this document if such data become published.

\section{Conclusion}

This rapid review summarizes highest quality evidence and provides evidence-based and trustworthy recommendations on the use of TaTME for low rectal cancer.

Supplementary Information The online version contains supplementary material available at https://doi.org/10.1007/s00464-022-09090-4.

Acknowledgements The steering group would like to thank Mrs. Lyudmil Ninov and the European Patients Forum for assisting in finding a patient representative to act as panel member in this guideline.

Funding This project was funded by United European Gastroenterology and the European Association for Endoscopic Surgery and Other Interventional Techniques. The funding bodies had no influence on the development of this rapid guideline. There is no grant number linked to this research.

\section{Declarations}

Conflict of interest Marco Milone, Alberto Arezzo, Elleke Dresen, George Theodoropoulos, Joe Mahaffey, Konstantinos Ferentinos, Luigi Boni, Marta Penna, Michel Adamina, Nader K. Francis, Nicole Bouvy, Nona Bejinariu, Katerina Maria Kontouli, Dimitris Mavridis, Per Olav Vandvik, and Stavros A. Antoniou have no direct conflicts of interest or financial ties to disclose. Indirect conflicts were documented and managed as per G-I-N standards. Detailed conflict of interest statements of all contributors can be found in http://osf.io/65vkq.

Disclaimer This clinical practice guideline has been developed under the auspice of the European Association for Endoscopic Surgery (EAES). It is intended to be used primarily by health professionals (e.g., surgeons, anesthetists, physicians) and to assist in making informed clinical decisions on diagnostic measures and therapeutic management. It is also intended to inform individual practice of allied health professionals (e.g., surgical nurses, dieticians, physical rehabilitation therapists, psychologists); to inform strategic planning and resource management by health care authorities (e.g., regional and national authorities, health care institutions, hospital administration authorities); and to inform patients wishing to obtain an overview of the condition of interest and its management.

The use of recommendations contained herein must be informed by supporting evidence accompanying each recommendation and by research evidence that might not have been published by the time of writing the present document. Users must, thus, base their actions informed by newly published evidence at any given point in time.

The information in the guideline should not be relied upon as being complete or accurate, nor should it be considered as inclusive of all proper treatments or methods of care or as a statement of the standard of care. With the rapid development of scientific knowledge, new evidence may emerge between the time the guideline is developed and when it is published or read. The guideline is not continually updated and may not reflect the most recent evidence. The guideline addresses only the topics specifically identified therein and is not applicable to other interventions, diseases, or stages of diseases. This guideline does not mandate any particular course of medical care. Further, the guideline is not intended to substitute the independent professional judgment of the treating provider, as the guideline does not necessarily account for individual variation among patients.

Even if evidence on a topic suggests a specific diagnostic and/or treatment action, users and especially health professionals may need to decide against the suggested or recommended action in view of circumstances related to patient values, preferences, co-morbidities and disease characteristics; available human, monetary and material resources; and healthcare infrastructures.

EAES provides this guideline on an "as is" basis, and makes no warranty, express or implied, regarding the guideline.

Open Access This article is licensed under a Creative Commons Attribution 4.0 International License, which permits use, sharing, adaptation, distribution and reproduction in any medium or format, as long as you give appropriate credit to the original author(s) and the source, provide a link to the Creative Commons licence, and indicate if changes were made. The images or other third party material in this article are included in the article's Creative Commons licence, unless indicated otherwise in a credit line to the material. If material is not included in the article's Creative Commons licence and your intended use is not permitted by statutory regulation or exceeds the permitted use, you will need to obtain permission directly from the copyright holder. To view a copy of this licence, visit http://creativecommons.org/licenses/by/4.0/.

\section{References}

1. The American Cancer Society medical and editorial content team: Key Statistics for Colorectal Cancer. 2020. Available in: https:// www.cancer.org/content/dam/CRC/PDF/Public/8604.00.pdf. Accessed July 15, 2021

2. Cancer Research UK: Bowel cancer incidence statistics. Available in: https://www.cancerresearchuk.org/sites/default/files/cancerstats/inc_anatomicalsite_bowel/inc_anatomicalsite_bowel.pdf. Accessed July 15, 2021

3. Vennix S, Pelzers L, Bouvy N, Beets GL, Pierie J-P, Wiggers T et al (2014) Laparoscopic versus open total mesorectal excision for rectal cancer. Cochrane Database Sys Rev. https://doi.org/10. 1002/14651858.CD005200.pub3

4. Simillis C, Lal N, Thoukididou SN, Kontovounisios C, Smith JJ, Hompes R et al (2019) Open versus laparoscopic versus robotic versus transanal mesorectal excision for rectal cancer: a systematic review and network meta-analysis. Ann Surg 270(1):59-68

5. Lacy AM, Tasende MM, Delgado S, Fernandez-Hevia M, Jimenez M, De Lacy B et al (2015) Transanal total mesorectal excision for rectal cancer: outcomes after 140 patients. J Am Coll Surg 221(2):415-423

6. Fearnhead NS, Acheson AG, Brown SR, Hancock L, Harikrishnan A, Kelly SB et al (2020) The ACPGBI recommends pause for reflection on transanal total mesorectal excision. Colorectal Dis 22(7):745-748

7. Kang L, Sylla P, Atallah S, Ito M, Wexner SD, Wang J-P (2020) taTME: boom or bust? Gastroenterology Report 8(1):1-4

8. Wasmuth HH, Faerden AE, Myklebust TA, Pfeffer F, Norderval S, Riis R et al (2020) Transanal total mesorectal excision for rectal cancer has been suspended in Norway. Br J Surg 107(1):121-130

9. Warrier SK, Bell S, Kong JC, Larach T, Heriot A (2020) Comments on: Transanal total mesorectal excision for rectal cancer has been suspended in Norway. British J Surg 107(7):e221

10. Larsen SG, Faerden AE, Wasmuth HH (2020) Author response to: Comment on: Transanal total mesorectal excision for rectal cancer has been abandoned in Norway. British J Surg 107(7):e222 
11. Adamina M, Buchs NC, Penna M et al (2018) St. Gallen consensus on safe implementation of transanal total mesorectal excision. Surg Endosc 32(3):1091-1103

12. Caycedo-Marulanda A, Brown CJ, Chadi SA, Ashamalla S, Lee L, Stotland P et al (2020) Canadian taTME expert collaboration (CaTaCO) position statement. Surg Endosc 34(9):3748-3753

13. Adamina $\mathrm{M}$ et al (2020) International expert consensus guidance on indications, implementation and quality measures for transanal total mesorectal excision. Colorect Dis 22(7):749-755

14. Zhu Z, Wang Y, Li F et al (2019) Comparison of clinicopathological features and prognosis between adenocarcinoma of esophagogastric junction and adenocarcinoma of gastric antrum. Zhonghua wei Chang wai ke za zhi Chinese J Gastrointestinal Surg 22(2):149-155

15. EAES Guidelines Subcommittee: Living review of surgical guidelines. Available in: https://eaes.eu/about-eaes/committees/conse nsus-guideline-subcommittee-projects/\#living-review. Accessed July 15, 2021

16. Milone M, Mavridis D, Antoniou SA: Protocol of EAES Rapid Guideline: TaTME. 2021. Available in: https://eaes.eu/wp-conte nt/uploads/2021/03/Protocol_-TaTME-for-Rectal-Cancer.pdf. Accessed July 15, 2021

17. Schünemann H, Brożek J, Guyatt G, Oxman A: Handbook for grading the quality of evidence and the strength of recommendations using the GRADE approach. Updated October 2013. Available in: https://gdt.gradepro.org/app/handbook/handbook.html. Accessed July 15, 2021

18. Institute of Medicine (US) Committee on Standards for Developing Trustworthy Clinical Practice Guidelines: Clinical Practice Guidelines We Can Trust. Washington (DC): National Academies Press (US) 2011. Available in: https://pubmed.ncbi.nlm.nih.gov/ 24983061/. Accessed July 15, 2021

19. Qaseem A, Forland F, Macbeth F, Ollenschläger G, Phillips S, van der Wees P et al (2012) Guidelines International Network: toward international standards for clinical practice guidelines. Ann Intern Med 156(7):525-531

20. Antoniou SA. Appendix files for EAES Rapid Guideline: TaTME. 2021. Available in: http://osf.io/65vkq. Accessed July 15, 2021

21. Guyatt GH, Oxman AD, Kunz R, Atkins D, Brozek J, Vist G et al (2011) GRADE guidelines: 2. Framing the question and deciding on important outcomes. J Clin Epidemiol 64(4):395-400

22. Sterne JAC, Savović J, Page MJ, Elbers RG, Blencowe NS, Boutron I, et al (2019) RoB 2: a revised tool for assessing risk of bias in randomised trials. BMJ. https://doi.org/10.1136/bmj.14898

23. Sterne JA, Hernán MA, Reeves BC, Savović J, Berkman ND, Viswanathan M, et al (2016) ROBINS-I a tool for assessing risk of bias in non- randomised studies of interventions. BMJ. https:// doi.org/10.1136/bmj.i4919

24. Hultcrantz M, Rind D, Akl EA, Treweek S, Mustafa RA, Iorio A et al (2017) The GRADE Working Group clarifies the construct of certainty of evidence. J Clin Epidemiol 87:4-13

25. Nikolakopoulou A, Mavridis D, Salanti G (2014) Demystifying fixed and random effects meta-analysis. Evid Based Ment Health 17(2):53-57

26. Schünemann H, Broże J, Guyatt G et al. GRADE Handbook: 5 Quality of evidence. Available in: https://gdt.gradepro.org/app/ handbook/handbook.html\#h.9rdbelsnu4iy. Accessed July 15, 2021

27. Schünemann HJ, Cuello C, Akl EA, Mustafa RA, Meerpohl JJ, Thayer K et al (2019) GRADE guidelines: 18. How ROBINS-I and other tools to assess risk of bias in nonrandomized studies should be used to rate the certainty of a body of evidence. J Clin Epidemiol 111:105-114

28. Pai M, Yeung CHT, Akl EA, Darzi A, Hillis C, Legault K et al (2019) Strategies for eliciting and synthesizing evidence for guidelines in rare diseases. BMC Med Res Methodol 19(1):67
29. Rubinkiewicz M, Nowakowski M, Wierdak M, Mizera M, Dembiński M, Pisarska M et al (2018) Transanal total mesorectal excision for low rectal cancer: a case-matched study comparing TaTME versus standard laparoscopic TME. Cancer Manag Res 10:5239-5245

30. Ren J, Liu S, Luo H, Wang B, Wu F (2021) Comparison of shortterm efficacy of transanal total mesorectal excision and laparoscopic total mesorectal excision in low rectal cancer. Asian J Surg 44(1):181-185

31. Detering R, Roodbeen SX, van Oostendorp SE, Dekker J-WT, Sietses C, Bemelman WA et al (2019) Three-year nationwide experience with transanal total mesorectal excision for rectal cancer in the netherlands: a propensity score-matched comparison with conventional laparoscopic total mesorectal excision. J Am College Surg 228(3):235-244

32. de'Angelis N, Portigliotti L, Azoulay D, Brunetti F, (2015) Transanal total mesorectal excision for rectal cancer: a single center experience and systematic review of the literature. Langenbeck's Arch Surg 400(8):945-959

33. Velthuis S, Nieuwenhuis DH, Ruijter TEG, Cuesta MA, Bonjer HJ, Sietses C (2014) Transanal versus traditional laparoscopic total mesorectal excision for rectal carcinoma. Surg Endosc 28(12):3494-3499

34. Perdawood SK, Thinggaard BS, Bjoern MX (2018) Effect of transanal total mesorectal excision for rectal cancer: comparison of short-term outcomes with laparoscopic and open surgeries. Surg Endosc 32(5):2312-2321

35. Veltcamp Helbach M, Koedam TWA, Knol JJ, Velthuis S, Bonjer HJ, Tuynman JB et al (2019) Quality of life after rectal cancer surgery: differences between laparoscopic and transanal total mesorectal excision. Surg Endosc 33(1):79-87

36. Roodbeen SX, Penna M, Mackenzie H, Kusters M, Slater A, Jones OM et al (2019) Transanal total mesorectal excision (TaTME) versus laparoscopic TME for MRI-defined low rectal cancer: a propensity score-matched analysis of oncological outcomes. Surg Endosc 33(8):2459-2467

37. Zeng Z, Luo S, Chen J, Cai Y, Zhang X, Kang L (2020) Comparison of pathological outcomes after transanal versus laparoscopic total mesorectal excision: a prospective study using data from randomized control trial. Surg Endosc 34(9):3956-3962

38. Matsuda T, Yamashita K, Hasegawa H, Fujikawa M, Sakamoto $\mathrm{H}$, Yamamoto $\mathrm{M}$ et al (2021) Clinical outcomes of transanal total mesorectal excision using a lateral-first approach for low rectal cancer: a propensity score matching analysis. Surg Endosc 35(2):971-978

39. Marks JH, Montenegro GA, Salem JF, Shields MV, Marks GJ (2016) Transanal TATA/TME: a case-matched study of taTME versus laparoscopic TME surgery for rectal cancer. Tech Coloproctol 20(7):467-473

40. Gordeyev SS, Dzhumabae KE, Mamedl ZZ, Kozlov NA, Surayeva YE, Fedyanin MY et al (2018) Transanal total mesorectal excision in selected patients with "difficult pelvis": a case-control study of "difficult" rectal cancer patients. Eur Surg 51:13-18

41. Chen C-C, Lai Y-L, Jiang J-K, Chu C-H, Huang I-P, Chen W-S et al (2016) Transanal total mesorectal excision versus laparoscopic surgery for rectal cancer receiving neoadjuvant chemoradiation: a matched case-control study. Ann Surg Oncol 23(4):1169-1176

42. Rubinkiewicz M, Zarzycki P, Witowski J, Pisarska M, Gajewska $\mathrm{N}$, Torbicz $\mathrm{G}$ et al (2019) Functional outcomes after resections for low rectal tumors: comparison of Transanal with laparoscopic Total Mesorectal excision. BMC Surg 19(1):79

43. Fernández-Hevia M, Delgado S, Castells A, Tasende M, Momblan D, Díaz del Gobbo G et al (2015) Transanal total mesorectal excision in rectal cancer: short-term outcomes in comparison with laparoscopic surgery. Annals Surg 261(2):221-227 
44. de Lacy FB, Roodbeen SX, Ríos J, van Laarhoven J, Otero-Piñeiro A, Bravo R, Visser T, van Poppel R, Valverde S, Hompes R, Sietses C, Castells A, Bemelman WA, Tanis PJ, Lacy AM (2020) Three-year outcome after transanal versus laparoscopic total mesorectal excision in locally advanced rectal cancer: a multicenter comparative analysis. BMC Cancer 20(1):677

45. Lee L, de Lacy B, Gomez Ruiz M, Liberman AS, Albert MR, Monson JRT et al (2019) A multicenter matched comparison of transanal and robotic total mesorectal excision for mid and lowrectal adenocarcinoma. Ann Surg 270(6):1110-1116

46. Di Candido F, Carvello M, Keller DS, Vanni E, Maroli A, Montroni I et al (2021) A comparative cost analysis of transanal and laparoscopic total mesorectal excision for rectal cancer. Updat Surg 73(1):85-91

47. Koedam TWA, Veltcamp Helbach M, van de Ven PM, Kruyt PM, van Heek NT, Bonjer HJ et al (2018) Transanal total mesorectal excision for rectal cancer: evaluation of the learning curve. Tech Coloproctol 22(4):279-287

48. Persiani R, Agnes A, Belia F, D’Ugo D, Biondi A (2020) The learning curve of TaTME for mid-low rectal cancer: a comprehensive analysis from a five-year institutional experience. Surg Endosc. https://doi.org/10.1007/s00464-020-08115-0

49. Poh K, Hong Y, Lao V, Krizzuk D, Da Silva-Southwick G, Nogueras J et al (2019) Assessment of learning curve of tatme by multidimensional cusum analysis. Dis Colon Rectum 62(6):e403-e404

50. Lee L, Kelly J, Nassif GJ, deBeche-Adams TC, Albert MR, Monson JRT (2020) Defining the learning curve for transanal total mesorectal excision for rectal adenocarcinoma. Surg Endosc 34(4):1534-1542
51. Chernyshov S, Rybakov E, Kazieva L, Shelygin Y (2018) Transanal total mesorectal excision: How many cases are necessary to overcome learning curve? Colorectal Dis 20:76

52. Palter VN, de Montbrun SL (2020) Implementing new surgical technology: a national perspective on case volume requirement for proficiency in transanal total mesorectal excision. Canadian J Surg 63(1):E21-E26

53. Atallah SB, DuBose AC, Burke JP, Nassif G, deBeche-Adams T, Frering $T$ et al (2017) Uptake of transanal total mesorectal excision in North America: initial assessment of a structured training program and the experience of delegate surgeons. Dis Colon Rectum 60(10):1023-1031

54. Study of NOTES-TME Versus L-LAR in Rectal Cancer (NOTESvsL-LAR). Available in: https://clinicaltrials.gov/ct2/show/ NCT02550769. Accessed July 16, 2021.

55. Transanal Total Mesorectal Excision Versus Robotic Total Mesorectal Excision (TaRo). Available in: https://clinicaltrials.gov/ct2/ show/NCT04091620. Accessed July 15, 2021

56. Transanal Versus Laparoscopic Total Mesorectal Excision For Rectal Cancer. Available in: https://clinicaltrials.gov/ct2/show/ NCT02966483. Accessed July 15, 2021

57. COLOR III Trial: Transanal vs Laparoscopic TME (COLOR III). Available in: https://clinicaltrials.gov/ct2/show/NCT02736942. Accessed July 15, 2021

58. Transanal Versus Laparoscopic Total Mesorectal Excision for Rectal Cancer. (taTME). Available in: https://clinicaltrials.gov/ ct2/show/NCT03413904. Accessed July 15, 2021

Publisher's Note Springer Nature remains neutral with regard to jurisdictional claims in published maps and institutional affiliations.

\section{Authors and Affiliations}

\section{Marco Milone ${ }^{1} \cdot$ Michel Adamina ${ }^{2,3} \cdot$ Alberto Arezzo $^{4} \cdot$ Nona Bejinariu $^{5} \cdot$ Luigi Boni $^{6} \cdot$ Nicole Bouvy $^{7}$. F Borja de Lacy ${ }^{8} \cdot$ Raphaëla Dresen $^{9} \cdot$ Konstantinos Ferentinos ${ }^{10,11} \cdot$ Nader K. Francis $^{12}$. Joe Mahaffey ${ }^{13}$. Marta Penna ${ }^{14} \cdot$ George Theodoropoulos $^{15} \cdot$ Katerina Maria Kontouli $^{16} \cdot$ Dimitris Mavridis $^{16,17} \cdot$ Per Olav Vandvik $^{18}$. Stavros A. Antoniou ${ }^{19}$}

1 Department of Clinical Medicine and Surgery, University "Federico II" of Naples, Naples, Italy

2 Department of Surgery, Clinic of Visceral and Thoracic Surgery, Cantonal Hospital Winterthur, Winterthur, Switzerland

3 Department of Biomedical Engineering, Faculty of Medicine, University of Basel, Allschwil, Switzerland

4 Department of Surgical Sciences, University of Torino, Torino, Italy

5 Department of Pathology, Santomar Oncodiagnostic, Cluj-Napoca, Romania

6 Department of Surgery, Fondazione IRCCS - Ca' Granda - Ospedale Maggiore Policlinico University of Milan, Milan, Italy

7 Department of Surgery, Maastricht University Medical Center, Maastricht, Netherlands

8 Department of Gastrointestinal Surgery, Institute of Digestive and Metabolic Diseases, Hospital Clinic of Barcelona, Barcelona, Spain

9 University Hospitals Leuven, Leuven, Belgium
10 Department of Radiation Oncology, German Oncology Center, Limassol, Cyprus

11 Present Address: European University Cyprus, Nicosia, Cyprus

12 Department of General Surgery, Yeovil District Hospital NHS Foundation Trust, Yeovil, UK

13 Fight Colorectal Cancer, Springfield, MO, USA

14 Oxford University Hospitals, Oxford, UK

15 First Department of Propaedeutic Surgery of Athens, Medical School, National and Kapodistrian University of Athens, Athens, Greece

16 Department of Primary Education, School of Education, University of Ioannina, Ioannina, Greece

17 Faculté de Médecine, Université Paris Descartes, Paris, France

18 Department of Health Management and Health Economics, University of Oslo, Oslo, Norway

19 Surgical Department, Mediterranean Hospital of Cyprus, Limassol, Cyprus 